\title{
Correction to: Brönsted acid hydrotrope combined catalysis in water: a green approach for the synthesis of indoloquinoxalines and bis-tetronic acids
}

\author{
Arjun Kumbhar ${ }^{1} \cdot$ Dhanaji Kanase ${ }^{2} \cdot$ Suhas Mohite $^{3} \cdot$ Rajshri Salunkhe $^{4}$. \\ Trushant Lohar ${ }^{2}$
}

Published online: 26 May 2021

(c) Springer Nature B.V. 2021

\section{Correction to: Research on Chemical Intermediates https://doi.org/10.1007/s11164-021-04430-w}

In the original publication of the article, the citation " 20 " was incorrectly linked to the DOI link "https://doi.org/10.1016\%2Fj.dyepig.2019.03.028". However, the correct DOI link should be "https://doi.org/10.1016/j.dyepig.2019.03.032".

The original article has been corrected.

Publisher's Note Springer Nature remains neutral with regard to jurisdictional claims in published maps and institutional affiliations.

The original article can be found online at https://doi.org/10.1007/s11164-021-04430-w.

Trushant Lohar

trushantlohar@gmail.com

1 Padmabhushan Dr. Vasantraodada Patil Mahavidyalaya, Tasgaon, Maharashtra 416 312, India

2 Bharati Vidyapeeth's Dr. Patangrao Kadam Mahavidyalaya, Sangli, Maharashtra 416 416, India

3 Bharati Vidyapeeth's Yashwantrao Mohite College of Arts, Science and Commerce, Pune, Maharashtra 411 038, India

4 Department of Chemistry, Shivaji University, Kolhapur, Maharashtra 416 004, India 